\title{
Augusto Guarino (Ed.), El doble de todas las cosas. Estudios sobre Ramón Gómez de la Serna, Nápoles, Tullio Pironti Editore, 2020, 319 pp.
}

Rosa Schioppa rschioppa@unior.it

Università degli studi di Napoli “L’Orientale”, Italia

Cita sugerida: Schioppa, R. (2021). [Revisión del libro $E l$ doble de todas las cosas. Estudios sobre Ramón Gómez de la Serna de A. Guarino (Ed.)]. Olivar, 21(33), e101. https://doi.org/10.24215/18524478e101

El volumen El doble de todas las cosas. Estudios sobre Ramón Gómez de la Serna, editado por Augusto Guarino, aspira a reubicar en el debate académico-literario a Ramón Gómez de la Serna, una de las figuras más interesantes de la cultura española del siglo XX, relegada durante mucho tiempo a los márgenes de un canon, muy a menudo, traicionero.

Ramón declinó la densidad de su universo intelectual de formas siempre diferentes, articulando su actividad literaria principalmente en torno a la revista "Prometeo" y la tertulia del Café de Pombo. Fue el gran inspirador de la modernidad y el precursor de la vanguardia. Su peculiar escritura y sus greguerías influyeron notablemente en la producción de los jóvenes poetas de los años veinte y arraigaron también en los modos literarios de los narradores de esa misma época (entre otros, Francisco Ayala, Benjamín Jarnés, Antonio Espina). Este elemento sería suficiente para desmontar “el tópico de Ramón (...) que pasó sin dejar huellas 
significativas en la literatura española” (p. 10). En la introducción del volumen, Augusto Guarino destaca precisamente esta falta de reconocimiento, señalándola como una de las causas de la progresiva marginación del canon, junto con la imposibilidad, indicada por algunos críticos, de identificar en la producción literaria del autor madrileño una "obra maestra" (p. 10).

El volumen colectivo ofrece un rico conjunto de voces articuladas en torno a dos polos fundamentales: por un lado, se propone un trabajo de fijación, análisis y reinterpretación de algunos momentos destacados de la producción de Ramón, ofreciendo nuevos ángulos de observación. Este es el caso de las contribuciones de Elide Pittarello, María José Flores Requejo, Isabel Román, Gennaro Schiano, Claudia Santamaría, Natasha Leal Rivas, Valeria Cavazzino, Raquel Macciuci, Rosalina Nigro. Por otro lado, se intenta identificar cómo, y en qué medida, la producción literaria de Ramón puede ser abordada y relacionada con otras expresiones literarias, culturales y artísticas, tanto en España como en otros países: véanse a este respecto los estudios de Gabriele Morelli, Davide Aliberti, Paola Laura Gorla, Luca Cerullo, Teresa Cirillo, Germana Volpe, Francesca De Rosa, Gerardo Grossi, Marco Ottaiano, Maria Alessandra Giovannini, Giuseppina Notaro. La publicación propone lúcidas reflexiones de especial importancia académica y da cabida a numerosas voces de jóvenes estudiosos, que se acompañan y dialogan con aquellas de expertos ya consagrados. Siguiendo el doble hilo identificado como guía para orientarnos, proponemos a continuación una lectura de algunos de los estudios contenidos en el volumen, que por razones de espacio se limitará a un número muy reducido de contribuciones, con el objetivo de arrojar luz sobre algunos aspectos que hacen que esta obra colectiva sea especialmente importante.

El primero de los dos grupos identificados incluye el ensayo de Isabel Román, quien, partiendo del estudio de las tres redacciones de El doctor inverosimil (1914; 1921; 1941), pretende ofrecer un análisis de los modos narrativos de Ramón. Al considerar esta obra como una cartografía de la poética del autor, la estudiosa nos ofrece una lectura de las diferentes declinaciones del ramonismo, destacando que el texto contiene algunas de las estrategias narrativas más exploradas por el autor madrileño. La estudiosa, en particular, se detiene en la prosa fragmentaria y "dispersa" (p. 82) del autor, destacando cómo Ramón hace de su escritura un lugar de contaminación entre géneros literarios. En la novela, en efecto, en el curso de los casos clínicos tratados por el Dr. Vivar, se alternan secciones más estrictamente narrativas con digresiones, a veces bastante extensas, de carácter ensayístico-teórico. Los casos clínicos tratados ejemplifican algunos de los malestares del hombre contemporáneo, y la autora los pone en correlación directa con el sistema de los objetos en la novela. En todas las obras de Ramón los objetos tienen una importancia clave, y también en esta obra adquieren centralidad, porque, como demuestra la autora al llamarlos "objetos malsanos" (p. 95), son a menudo la causa de los males con los que el doctor Vivar debe lidiar. La idea más interesante de la contribución reside en la observación de que la novela está formada por una "antología de greguerías", que buscan su propia coherencia al articularse en torno al cuerpo humano, que constituye una especie de fil ronge, y que funciona como "aglutinante principal" (p. 106).

El ensayo de Raquel Macciuci pretende analizar las polémicas político-ideológicas vinculadas a la inconstante fortuna del autor, partiendo de dos elementos: en primer lugar, se investiga la relación del escritor madrileño con el movimiento de vanguardia; en segundo lugar, se explora la etapa argentina de Ramón, y se examinan algunas hipótesis sobre las causas del progresivo ostracismo (literario, simbólico y emocional) del que fue víctima el autor, centrándose en particular en su relación con el franquismo y con el gobierno de Perón. Con referencia al primero de los dos elementos, la estudiosa muestra que hay muchos puntos de contacto entre las obras de Ramón y aquellas de las vanguardias históricas; la autora señala, con razón, que "en 1909 Ramón Gómez de la Serna sienta las bases de la vanguardia en España" (p. 209). El principio de los años treinta, con el final de la dictadura de Primo de Rivera y la instauración de la república, marcó un punto de ruptura entre la experiencia literaria de Ramón y la experiencia de los intelectuales de la vanguardia, que dejaron de lado el dogma del "arte por el arte" ante la necesidad de intervenir de forma más consistente en la esfera pública. En cambio, Ramón se movió en la dirección contraria, continuando con la defensa a 
ultranza de la separación irreconciliable entre arte y política, negándose a acercarse a la literatura social, y permaneciendo en lo que Macciuci llama «El anacronismo de su imaginario estético» (p. 225). En cuanto a la investigación del periodo argentino del autor, la estudiosa señala que, aunque en las últimas décadas algunas aportaciones críticas han reducido el peso del elemento ideológico en el proceso de marginación de su obra, la actitud que el autor mantuvo ante dos contextos políticos problemáticos (el franquismo y el peronismo) siguió jugando un papel importante en lo que la estudiosa denomina las "dos marginaciones". La investigadora escribe que Ramón, a pesar de ser extremadamente refractario a conectar la literatura con otras esferas sociales, y a pesar de su posición de sustancial neutralidad ante la guerra civil, al final del conflicto apoyó al régimen de Franco ("primera marginación”, p. 217). La "segunda marginación” (p. 222) de Ramón, según Macciuci, ha de ser relacionada con su apoyo al gobierno de Perón, al que se opusieron las élites intelectuales argentinas, que, si bien podían admitir las ambiguas relaciones de Ramón con la dictadura española, no podían tolerar absolutamente su apoyo al peronismo.

Pasemos ahora a enfocar la discusión hacia algunas de las contribuciones centradas en la exploración de las relaciones existentes entre la escritura de Ramón y otras expresiones literarias y culturales. La contribución de Gabriele Morelli, uno de los mayores expertos italianos de la Generación del 27, pretende investigar el estrecho vínculo entre los modos poéticos de los jóvenes autores del 27 y las formas estéticas exploradas por Ramón. Morelli destaca que el principal elemento de novedad de la escritura del autor madrileño reside "en la aventura de la palabra” (p. 21). Con esta eficaz expresión, el estudioso demuestra que el valor intrínseco de la obra de Ramón, que fue recogida por la generación poética de la década de los veinte, reside en la experimentación lingüística y en la exploración de nuevas posibilidades expresivas. En particular, mediante el uso de la metáfora, el autor rompe la correlación lógica que existe entre el referente y su declinación literaria y, a través de su mirada subjetiva, desactiva el automatismo interpretativo del lenguaje cotidiano. Según Morelli, los autores de la Generación del 27 se acercaron a los métodos de escritura de Ramón precisamente por este renovado gusto estético, caracterizado por la atención a los nuevos modos literarios explorados en Europa, y por la experimentación lingüística, que para los jóvenes autores que gravitaban en torno a la Residencia de Estudiantes se había convertido en una herramienta indispensable para distanciarse del sentido común típicamente afirmado por el canon burgués.

El ensayo de Maria Alessandra Giovannini se inscribe en esta misma línea de investigación, porque conecta el universo creativo de Ramón con la producción literaria contemporánea. Su estudio, en efecto, se centra en el análisis de la reverberación, "nunca precisada, pero sí evidente" (p. 299), de las estructuras y modalidades ramonianas en la escritura de Juan José Millás. Como muestra la estudiosa, la narrativa ramoniana viene a ser un antecedente de la novela del autor valenciano, por un lado por las reflexiones sobre la metanarratividad - desarrolladas por Ramón desde un punto de vista teórico, y en su declinación más propiamente creativa - que son retomadas, en distinta medida, por los autores contemporáneos y posmodernos, y por otro por los diferentes niveles de lectura de estas obras: uno más superficial, y vinculado a la 'experimentabilidad' de la palabra, el otro vinculado a un nivel más profundo, conectado a una lectura más compleja, y vinculado a varios niveles de significación. En particular, en relación con este último aspecto, la estudiosa muestra cómo en las obras de los dos autores se desarrolla una reflexión sobre el papel de la escritura en la construcción de la subjetividad y sobre el sentido último de la escritura en la construcción y comprensión de la realidad. Giovannini señala que las obras de ambos autores se sitúan en un espacio liminal, y dan vida a "un mundo donde la frontera entre lo real y lo imaginario, el yo y la nada, los hombres y las cosas, son rediseñados y esfumados" (p. 305), haciendo de la obra un lugar poroso de experimentación entre el mundo de lo real y el mundo de lo posible.

La publicación, por la variedad de temas tratados, representa sin duda una herramienta crucial para los estudiosos e investigadores, tanto para los expertos en la trayectoria literaria del genio madrileño, como para quien quiera acercarse por primera vez a su ilimitado universo creativo. Las nuevas perspectivas propuestas, reunidas en torno a los dos polos investigativos identificados anteriormente, permiten una doble línea de 
interpretación: una reservada a la reconstrucción de las principales coordenadas de la escritura de Ramón, y otra que intenta poner en diálogo las coordenadas establecidas con otras experiencias literarias y creativas. El texto, que se interroga acerca de las razones de la marginación de Ramón Gómez de la Serna, consigue establecer nuevos núcleos críticos de referencia, y hace que el proceso de renegociación de la presencia de su escritura en el canon avance, especialmente por la huella que esa modalidad narrativa - fundacional de la modernidad literaria hispánica - ha dejado tanto en las obras de las generaciones inmediatamente posteriores a la época de Ramón, como en las manifestaciones literarias mucho más recientes. 